\title{
SUSTENTABILIDADE E AGRONEGÓCIO: ALINHAMENTOS AO PROCESSO DECISÓRIO EM UMA EMPRESA RURAL
}

\author{
SUSTAINABILITY AND AGRIBUSINESS: ALIGNING WITH THE DECISION MAKING \\ PROCESS IN A RURAL COMPANY
}

\author{
Tatielle Belem Langbecker
}

Universidade Federal de Santa Maria - UFSM, RS, Brasil, tatielle.belem@gmail.com

\section{Thiago Antonio Beuron}

Universidade Federal do Pampa - UNIPAMPA, RS, Brasil, thiagobeuron@unipampa.edu.br

\begin{abstract}
Resumo: Este artigo tem por objetivo verificar as configuraçóes dos preceitos da sustentabilidade ao processo decisório em determinada empresa rural em Dom Pedrito/RS. O estudo caracterizou-se como exploratório e descritivo fundamentado na pesquisa qualitativa adotando a estratégia de estudo de caso. Foi realizada entrevista, como base em roteiro semiestruturado, em que o caso pesquisado representa situação emblemática para o agronegócio da região da Campanha. Os procedimentos de análise foram direcionados à análise de conteúdo temático-categorial. A motivação para inserir a sustentabilidade como um elemento do processo decisório perpassa tanto pela primazia da consciência sustentável como exerce função estratégica no posicionamento de mercado. Por fim, os resultados encontrados foram acordes com os pilares da sustentabilidade. Trata-se de uma empresa rural que os aplica em seu cotidiano e em suas estratégias, ressaltando o viés com a perspectiva ambiental.
\end{abstract}

Palavras-chave: Agronegócio. Sustentabilidade. Tomada de decisão. Campanha Gaúcha.

\begin{abstract}
This article aims to verify the configurations of sustainability precepts to the decision making process in a given rural company in Dom Pedrito/RS. The study was characterized as exploratory and descriptive based on qualitative research adopting the case study strategy. An interview was conducted, based on a semi-structured script, in which the case surveyed represents an emblematic situation for agribusiness in the Campanha region. The analysis procedures were directed to thematic-categorical content analysis. The motivation to insert sustainability as an element of the decision-making process goes as much through the primacy of sustainable awareness as it plays a strategic role in market positioning. Finally, the results were agreed with the pillars of sustainability. It is a rural company that applies them in their daily lives and strategies, emphasizing the bias with the environmental perspective.
\end{abstract}

Keywords: Agribusiness. Sustainability. Decision making. Campanha Gaúcha. 


\section{Introdução}

As discussões sobre o agronegócio, gradativamente, ampliam o portfólio de temáticas debatidas na academia. A ideia de que falar em agronegócio remete exclusivamente às economias de escalas, mercados internacionais e afins, já se esgotou e, não faz pouco tempo. No início dos anos 2000, Jacques Marcovitch ao referir-se sobre o conceito de agribusiness, no prefácio de uma importante obra sobre o agronegócio - Economia e Gestão dos Negócios Agroalimentares - salienta que "definições não são definitivas" e, que a ideia compacta e simplificadora do agronegócio como uma "corrente" em que cada operação se diz um elo "não traduz seu alcance real". "É muito mais do que isso" (Marcovitch, 2000, p. IX).

Alguns aspectos relacionados à discussão desencadeiam novos desafios relacionados, por exemplo, à preocupação da sociedade quanto às questões da sustentabilidade ambiental. Essa questão desencadeia, ou melhor força de certa forma, a adaptação do agronegócio em suas formas de produzir conduzindo a produções sustentáveis, mais limpas e, intensifica as tendências de um mercado mais exigente quanto às certificações que identifiquem critérios de produção ambientalmente corretos (Claudino e Talamini, 2013).

As demais dimensões da sustentabilidade - social e econômica, além da ambiental - também passam a compor o rol de problemáticas a serem discutidas e consideradas nos processos decisórios das empresas (Maia e Pires, 2011), sejam industriais, comerciais, urbanas ou rurais. Os autores enfatizam a complexidade em inserir o conceito de sustentabilidade na tomada de decisão, pois há que se considerar concomitantemente as três dimensões da sustentabilidade.

A importância do agronegócio para o Brasil é inegável. Autores como Claudino e Talamini (2013) atestam sua relevância em diversos aspectos, tais como, potencialidades das produções brasileiras como substitutas de produtos importados, contribuindo para a garantia de alimentos baratos e de qualidade aos brasileiros, geração de empregos, potencial mercado para o suprimento de alimentos em nível mundial, dentre outros aspectos que fazem do agronegócio brasileiro destaque tanto no cenário local quanto internacional.

Anterior a percepção da lógica sistêmica frente às dinâmicas socioeconômicas que permeiam o agronegócio, a Revolução Verde revelou processos de modernização da agricultura que intensificaram as atividades produtivas de modo a focalizarem ao máximo índices de produtividade contribuindo, progressivamente, para a insurgência das questões relativas à sustentabilidade, por exemplo. Junto a isso, o processo decisório também atuou como um dos motivadores da emergência da inserção da sustentabilidade nas organizações, pois vários problemas socioambientais surgem de decisões simplistas e carentes de uma visão sistêmica, somente com foco no econômico (Maia e Pires, 2011).

Ainda assim, a inserção dos preceitos da sustentabilidade, em suas diferentes dimensões, nos diferentes tipos de decisão do produtor rural se torna cada vez mais emergente, justificando esta pesquisa. E mais, investigar a importância dos diferentes componentes do agronegócio em um ambiente onde a economia local e regional tem como base consolidadas cadeias produtivas fundamentadas na produção rural, é tarefa e responsabilidade da universidade, especialmente, quando a problemática dispende esforços em contribuir com os caminhos para a sustentabilidade. 
Para problematizar o debate, destaca-se a economia do Rio Grande do Sul historicamente baseada em atividades produtivas rurais, tanto agrícolas como pecuárias. A expressividade econômica do agronegócio gaúcho verifica-se, por exemplo, através das exportações brasileiras - dados até dezembro de 2018 - representando 12,11\% de todas as exportações do agronegócio brasileiro, ocupando a $4^{\mathrm{a}}$ colocação no país (Brasil, 2018).

A soja e o arroz se destacam no agronegócio gaúcho representando as duas principais culturas agrícolas do estado. Na pecuária, a produção de leite e o frango ganham destaque, ainda se citam as produções de uvas, fumo, suínos, milho, maçã, entre outras que dinamizam o rural do Rio Grande do Sul (Feix e Leusin, 2015). Ao estreitar mais a unidade de análise geográfica, nota-se que, de acordo com dados do Instituto Brasileiro de Geografia e Estatística [IBGE] (2017), a Mesorregião Sudoeste Rio-Grandense se destaca na produção de arroz em casca, primeira colocação, dentre as Mesorregiões do Estado, com mais de 3,7 milhões de toneladas produzidas em 2017 e, na produção de soja em grão, em 2017, ocupou a terceira colocação com mais de 1,7 milhões de toneladas.

Dentre as Microrregiões que compõem o Sudoeste, a Campanha Meridional produziu, em 2017, mais de 437 mil toneladas de soja em grão e mais de 621 mil toneladas de arroz em casca. Outra atividade que ganha espaço é o cultivo da uva na Campanha Meridional, em 2017 a quantidade produzida cresceu aproximadamente $32 \%$ em relação ao ano anterior, alcançando 2.850 toneladas (IBGE, 2017).

A partir disto, destaca-se o município de Dom Pedrito, inserido na Microrregião da Campanha Meridional, como responsável por parte significativa da produção em relação à sua Micro e Mesorregião, assim como frente ao Rio Grande do Sul. A produção de soja, em 2017, alcançou mais de 231 mil toneladas e a de arroz mais de 411 mil toneladas. Na pecuária o efetivo de bovinos, com destaque para a pecuária de raças europeias, ultrapassou as 349 mil cabeças de gado e o efetivo ovino mais de 117 mil animais (IBGE, 2017). Os dados apresentados expressam a importância do agronegócio para o município e região.

Apesar disso, há a problemática que revela o baixo uso de ferramentas de gestão e controles nas atividades rurais (Andreatta, 2009). Daí a importância em estudar processos decisórios em contextos rurais, incorporando elementos que incluam mais que a visão estritamente econômica de uma atividade produtiva (Dalcin, 2010). Assim, se faz fundamental a inserção de elementos atrelados à sustentabilidade no estudo dos processos decisórios no rural, pois este é tão complexo quanto as dinâmicas que o circundam.

Todavia, parte das atividades produtivas rurais estão inseridas em dinâmicas mais estruturadas, aproximando-se da lógica praticada pelo setor empresarial. Ainda assim, em grande medida, há uma relação ímpar com o rural que distingue ser empresário na cidade ou no campo. Nesse sentido questiona-se: como os preceitos da sustentabilidade podem ser encontrados no processo decisório em determinada empresa rural situada no município de Dom Pedrito? Para isso, o objetivo geral se configura da seguinte forma: verificar as configurações dos preceitos da sustentabilidade ao processo decisório em determinada empresa rural em Dom Pedrito/RS. E os objetivos específicos centram-se em três: caracterizar o processo decisório de uma empresa rural; apontar os critérios de sustentabilidade 
no processo decisório; verificar a motivação em inserir a sustentabilidade como elemento do processo decisório.

\section{Sustentabilidade no agronegócio}

As constantes mudanças no cenário mundial, sejam em termos políticos, econômicos, sociais e ambientais, exige das empresas adaptações dos modelos de gestão para que assim permanecem no mercado de modo competitivo. Essas mudanças irão refletir diretamente nos modelos de avaliação de desempenho, respondendo na forma como será estruturada a tomada de decisão e a realização de controles. Uma dessas mudanças, atualmente, remete à inserção da sustentabilidade em âmbito empresarial, expondo as organizações à novas reflexões estratégicas e operacionais (Mamede, 2013).

O agronegócio é um dos setores que tem inserido em seu cotidiano o conceito de sustentabilidade. Para além, Paz, Iserhard e Kipper (2015) remetem a importância em pensar as atividades do agronegócio a partir de uma perspectiva sistêmica. Do mesmo modo referem-se à estrutura de indicadores e, à visão sistêmica presente nesses instrumentos como enriquecedora da percepção sobre o todo e suas interdependências, potencializando o reconhecimento estratégico da empresa, seus problemas, busca por novos caminhos e até mesmo permitindo verificar o quão vinculadas a sustentabilidade se fazem as diversas funções da empresa.

É a partir de um olhar sistêmico que a perspectiva da sustentabilidade e as suas dimensões emergem no dia a dia do agronegócio. Nesse sentido, Silva (2012) enfatiza que são inúmeras as variáveis consideradas para se tratar de sustentabilidade, porém encontram-se elementos comuns nas diferentes definições, possibilitando concordâncias de fatores utilizados para avaliar a sustentabilidade em uma organização. Parte desta compatibilidade refere-se ao que Elkington (1999) - referência sobre os pilares da sustentabilidade - denominou como "Triple Bottom Line", ou melhor, os três pilares da sustentabilidade - econômico, social e ambiental.

O conceito do tripé da sustentabilidade, criado por Elkington (1999), reforça a importância das empresas trabalharem estrategicamente a fim de manterem a sustentabilidade econômica, social e ambiental. A primeira sustenta o gerenciamento de empresas lucrativas e geradoras de valor; a segunda defende o estímulo a atividades voltadas à educação, cultura, justiça social envolvendo a comunidade presente no ambiente onde a empresa se insere e, a além disso, a terceira prima pela responsabilidade com o meio ambiente, por meio de programas de reciclagem e preservação, por exemplo (Paz, Iserhard, e Kipper, 2015).

Ressaltando os princípios dos três pilares da sustentabilidade, Allegretti (2013, p. 35) afirma que o tripé "propõe um modelo que leve em conta a qualidade ambiental, a justiça social e o desenvolvimento econômico". O intuito é dar seguimento a uma lógica que prese pelo equilíbrio entre o uso racional dos recursos do meio ambiente, garantindo as gerações seguintes uma sociedade justa, melhoria da saúde ambiental e melhoria de qualidade de vida.

Nas empresas brasileiras as dimensões da sustentabilidade que mais se destacam são a ambiental e a econômica e, a social surge de modo incipiente, em que poucas ações são desenvolvidas. Nas atividades de produção rural, as práticas relacionadas à sustentabilidade ambiental estão, em grande 
parte, relacionadas à utilização de agroquímicos. E, a econômica à rentabilidade e lucratividade. Apesar da noção sobre a sustentabilidade perpassar diferentes espaços de discussões, nas práticas empresariais, por vezes, esta fica aquém do esperado (Callado, 2010).

O estudo realizado por Mamede (2013) investigou empresas, localizadas em Portugal, dos setores da indústria, comércio e serviços a fim de identificar a utilização, valorização e disponibilidade de indicadores de sustentabilidade empresarial. Da mesma forma como se nota em estudos realizados no Brasil, a dimensão que mais dispende a atenção dos gestores é a econômica. Podem ser percebidas algumas diferenças entre os setores empresariais, por exemplo, na indústria se observou maior atenção com as determinantes internas, ou seja, medidas centradas nas performances dos produtos e satisfação dos clientes, porém estas baseadas em preceitos e indicadores econômicos.

Em relação ao agronegócio, a discussão da sustentabilidade centra-se sob à perspectiva ambiental, pois algumas formas de produção admitem a utilização de insumos e práticas intensivas, por vezes, nocivas ao meio ambiente. Ainda assim, há que expandir a visão acerca da sustentabilidade e considerar as dimensões social e econômica concomitantemente, a fim de proporcionar melhoria de qualidade de vida para a sociedade, organizações economicamente sustentáveis e sujeitos socialmente sustentáveis (Silva, 2012).

Percebendo a emergência em discutir problemáticas que envolvam o caráter social do tripé da sustentabilidade, Beuron, Madruga, Ávila, Galvão e Schuch (2014) abordaram o viés da dimensão social, motivados pelas discussões que prezam pela importância da inserção de uma gestão mais sustentável, para que não se reproduzam apenas discursos sobre a sustentabilidade empresarial. A empresa estudada pelos autores é reconhecida por sua postura sustentável, mas mesmo assim, por vezes a problemática não se torna atrativa ao conhecimento dos funcionários. É necessário trabalhar de forma estrutural, pois como se trata de um fenômeno cultural, as organizações passam a se responsabilizarem pela transmissão de valores sustentáveis buscando atingirem a reprodução dos mesmos por parte de seus funcionários (Beuron et al. 2014).

Corroborando com a discussão, em estudo realizado com empresas do agronegócio localizadas na Campanha do RS, 40\% das empresas participantes da pesquisa não utilizam indicadores que contemplem o tripé da sustentabilidade, inclusive $21 \%$ das empresas revelaram que, indicadores desta natureza, não se enquadram em seus negócios. Ainda foi constatado que as principais ações de sustentabilidade, mencionadas pelas empresas, voltam-se ao atendimento de legislação ambiental, além da tendência ao controle financeiro, o que remete ao fator econômico da sustentabilidade (Paz, Iserhard, e Kipper, 2015).

A percepção de elementos motivadores por parte dos funcionários reafirma a importância da dimensão social para a sustentabilidade empresarial. Em estudo realizado em uma empresa, os funcionários afirmaram a importância de fatores que os motivam a trabalhar: preocupação com a competitividade da empresa, com o coletivo e com a imagem da empresa, estímulos à inovação e criatividade, reconhecimento da competência dos funcionários e a construção da tradição na empresa. Com isso, tem-se subsídios para repensar os valores e metas da organização alicerçados nos interesses organizacionais, ou melhor, em parte do que representa a dimensão social da sustentabilidade de uma empresa (Beuron et al., 2014). 
Ainda que haja o reconhecimento da importância de se avaliar similarmente os aspectos econômicos, ambientais e sociais, uma pesquisa realizada com gestores do agronegócio na Argentina revelou que a relação estabelecida entre as compensações de cada fator, demonstra desigualdade no tratamento entre as variáveis, tais como já comentado. As preocupações com o econômico prevalecem, porém, neste caso, motivadas, várias vezes, pelo cumprimento com as obrigações sociais da família e dos funcionários (Arora, Peterson, Bert, e Podesta, 2016).

Em suma, "a gestão equilibrada entre as três dimensões é ainda uma prática pouco utilizada" (Mamede, 2013, p. 104), embora a adoção dos pilares da sustentabilidade tenha contribuído de maneira estratégica na diferenciação de produtos e inserção em determinados mercados (Silva, 2012). Nota-se que são inúmeras as tecnologias que surgem na busca da sustentabilidade, porém, geralmente, focam ações e resultados a curto prazo desconsiderando os possíveis efeitos a longo prazo. A busca pela sustentabilidade pode iniciar em atitudes mais simples como a tomada de decisões mais conscientes (Maia e Pires, 2011).

\subsection{Tomada de decisáo}

O processo de tomada de decisão responde como fator fundamental para os encaminhamentos estratégicos, táticos e operacionais de quaisquer organizações que sejam, desde pequenas empresas, grandes corporações internacionais até os diversos tipos de atividades rurais, contemplando desde a agricultura empresarial até os pequenos produtores.

A teoria da administração, inicialmente, negligenciava os processos decisórios motivada por uma visão mecanicista e funcionalista que entendia as decisões de uma organização, exclusivamente, focadas na maximização dos lucros. Assim, os elementos considerados nas decisões organizacionais eram baseados apenas na relação custo-benefício e, acreditava-se que os melhores resultados eram alcançados naturalmente (Löbler, 2005).

Ao longo dos períodos, os modelos de decisão passam a ser estudados e aos poucos adquirem características que não mais os reduzem à lógica estritamente quantitativa utilitarista. Conforme Löbler (2005) os estudos de Simon deixaram grandes contribuições que consideram mais que números e lucros, que revelam a complexidade atual das organizações. Uma das constatações de Simon revela que, além do gestor estar limitado ao desconhecimento da totalidade das consequências de suas decisões, as pressões sociais e pessoais também interferem no processo decisório.

Em concordância com algumas ideias de Simon apresentadas por Löbler (2005), o processo decisório é influenciado pelas ideias e valores dos atores que o representam, bem como pelas inter-relações entre diferentes atores, sejam relações conflituosas ou de interesses semelhantes. A dinamicidade e instabilidade dessas relações entre os diversos atores pode modificar-se respondendo diretamente no processo decisório (Moritz e Pereira, 2006).

Em termos gerais, segundo Moritz e Pereira (2006), pode-se afirmar que, independente dos modelos de decisão que a teoria apresenta - modelos clássico, comportamentalista, normativo, racional, entre outros -, os processos de tomada de decisão ganham características específicas acordes com as particularidades das organizações e o seu contexto. A gestão e o processo de tomada de 
decisão no ambiente rural podem exemplificar algumas dessas especificidades, pois como afirmam Batalha (2008) as diferentes atividades praticadas nesse ambiente, tanto pecuárias quanto agrícolas, apresentam particularidades como sazonalidade, perecibilidade e variações de qualidade da matériaprima, assim como, variáveis de consumo e produto final.

Além das especificidades encontradas no ambiente rural, determinantes no processo de tomada de decisão do produtor, os estabelecimentos rurais, de modo geral, organizam-se com a intenção de satisfazer as necessidades dos indivíduos inseridos em tal estabelecimento. Com isso, parte dos estabelecimentos agrícolas utilizam-se de uma associação de diversos elementos para suas decisões, como, aspectos técnicos, fatores vinculados à família, ideias e costumes dos agricultores e fatores externos (Andreatta, 2009).

Nesse sentido, alguns estudos foram, e são, realizados no intuito de compreender como se dá a tomada de decisão, especialmente, nas diferentes dinâmicas produtivas do ambiente rural. Para Dalcin (2010), é fundamental a inclusão de elementos sociais, culturais, institucionais, organizacionais e pessoais para o estudo do processo de tomada de decisão na agricultura, já que neste segmento não se pode afirmar que as decisões sejam fundamentadas apenas ao viés econômico, ou que estejam estritamente associadas a ele. Desta forma, a autora destaca a importância em visualizar a propriedade como um todo, para de fato entender como funciona o processo decisório na multiplicidade das propriedades encontradas no rural.

Fonte et al. (2016) também destacam a relevância em conhecer como se dá o processo de tomada de decisão em organizações da agricultura, independentemente do tamanho, escala e escopo da produção, visto a importância que o agronegócio exerce sobre a economia brasileira. Os autores revelam que, de modo geral, os gestores rurais pesquisados afirmam que os problemas relacionados à produção se centram nas seguintes perguntas: o que, quanto, quando e onde produzir? O questionamento sobre como produzir não é mencionado, ao menos de maneira explícita, por Fonte et al. (2016) em seus resultados. Isso provoca indagações sobre onde estaria a sustentabilidade nesse contexto.

Apesar disso, a sustentabilidade está cada vez mais presente nas discussões cotidianas, talvez pelo incompleto entendimento do que se trata. A questão que surge, nesse contexto, é como inserir a sustentabilidade nas atividades dos negócios? É a partir daí que surge a discussão da sustentabilidade como um processo de tomada de decisão. Arora et al. (2016) discutem essa problemática a partir de quatro aspectos: a incerteza como elemento indissociável à tomada de decisão, a ponderação entre os três pilares da sustentabilidade não é estática, ou melhor, modifica-se em acordo com o contexto, mas continua sendo crucial para o tomador de decisão; as decisões em acordo com o contexto socioeconômico e político do gestor, como priorizam e realizam as compensações entre as três dimensões e, por último, o papel do risco sobre o processo de tomada de decisão (Arora et al., 2016).

Pensando na sustentabilidade como um processo da tomada de decisão, Maia e Pires (2011, p. 195) propuseram um ensaio teórico que encaminha à compreensão da sustentabilidade a partir da ótica da tomada de decisão, sendo "classificadas em três níveis de complexidade: decisões simples, medianas e complexas". No intuito de estabelecer a relação entre os níveis de decisão e as dimensões da sustentabilidade, os autores determinam que os critérios encontrados na dimensão financeiras, são fluxo de caixa (pagamentos, recebimentos), investimentos, treinamentos, marketing, financiamentos, 
dentre outros. A dimensão social está relacionada ao bem-estar de todas as pessoas envolvidas com a organização, assim como, a responsabilidade social. E, a ambiental engloba todo o gerenciamento do ciclo de vida dos produtos trabalhados pela empresa.

A partir daí, Maia e Pires (2011, p. 200) estabeleceram uma “matriz dos níveis de complexidade das decisões direcionadas à sustentabilidade". As decisões mais simples tendem a considerar a dimensão econômica, visto que parte considerável das organizações focam suas decisões no econômico. As decisões medianas permanecem considerando em primeira mão o econômico, para na sequência, em acordo com a conveniência para a empresa, atender o social ou ambiental. E nas decisões complexas, busca-se atender as três dimensões da sustentabilidade simultaneamente, ou melhor, parte-se de um enfoque sistêmico.

\section{Método}

A pesquisa caracteriza-se de acordo com dois dos três níveis propostos por Gil (2008), exploratória e descritiva. A pesquisa exploratória, geralmente é a primeira fase, voltada para o aperfeiçoamento do delineamento teórico e empírico de uma temática a ser pesquisada. Portanto, como buscou-se investigar a associação entre duas temáticas em um contexto específico de empresa do agronegócio, o caráter exploratório contribui com a aproximação da problemática e apontamento de lacunas proporcionando uma visão geral sobre o tema. A pesquisa descritiva complementa na sequência, pois descreve a empresa em estudo apresentando seus principais delineamentos e relações com a sustentabilidade e tomada de decisão.

Em suma, por se tratar de uma problemática recente, as contribuições exploratórias e descritivas colaboram para o seu aprimoramento e deixam espaços para novas pesquisas em diferentes contextos. Também corrobora com as características de um estudo qualitativo, pois em primeira mão definiuse o objeto de estudo, e partiu-se à construção da problemática. Esta sequência ocorre em função da pesquisa qualitativa empenhar-se em expor a complexidade do contexto investigado (Flick, 2004).

\subsection{Estudo de Caso}

Esta seção delineia a pesquisa com base no método utilizado, o estudo de caso. Optou-se por este método, pois este caracteriza-se por enfocar eventos contemporâneos que não podem ser controlados pelo pesquisador; ainda se destaca que estudos de caso se concentram em problemáticas que investigam questões direcionadas ao "como" ou "por que" dos eventos foco (Yin, 2015).

As possibilidades que o estudo de caso proporciona, através da observação minuciosa, revelam uma perspectiva de geração de conhecimento específica que busca, primeiramente, peculiaridades do caso que o tornem singular, assim como, elementos que o identifiquem em um conjunto pré-definido de casos (Mariotto, Zanini, e Moraes, 2014). Pensando nisso, o caso em estudo contempla as duas características mencionadas pelos autores, pois, trata-se da única empresa rural - até o momento da pesquisa - a obter $100 \%$ de sua energia através de fontes renováveis e, com isso, qualificando-a no conjunto pré-definido de empresas rurais que estejam empenhadas em associar sustentabilidade à tomada de decisão. 
Desta forma, dentre os quatro tipos de estudos de caso trazidos por Yin (2015), esta pesquisa se apoia no tipo 1, ou melhor, o estudo de caso único em que se observa apenas uma unidade de análise. O autor argumenta que a peculiaridade do caso pode ser um dos elementos que dê suporte à justificativa da escolha do caso único como estratégia de investigação. Nesse sentido, como mencionado, tratase de um caso peculiar que se distingue da realidade contextual em que se insere tanto em esfera municipal, regional, assim como nacional.

\subsection{Procedimentos metodológicos}

O estudo de caso prevê a utilização de diferentes fontes de evidências para garantir sua consistência e confirmação das informações. Levando em conta estas proposições de Yin (2015), destaca-se as três principais fontes de evidências utilizadas nesta pesquisa: entrevistas, observações diretas e material disponível online na página da empresa. Em relação ao roteiro conduzido na entrevista realizada, este foi elaborado com base na teoria, focando na problemática de interesse. O instrumento passou por avaliação de pesquisador especialista na área de estudos sobre sustentabilidade.

Destaca-se que o instrumento considerou categorias pré-definidas (sustentabilidade ambiental, econômica e social e relações da sustentabilidade com a tomada de decisão) para a posterior análise. Essa técnica de geração de dados permitiu conduzir a entrevista e responder as inquietações sobre a inserção da sustentabilidade na tomada de decisão em empresas do agronegócio, já que para Gil (2008) a entrevista é uma forma de interação social que permite ao pesquisador obter informações úteis à investigação. Optou-se por perguntas abertas que permitiram maior liberdade do entrevistado em discorrer sobre sua realidade (Minayo, 2007).

A realização da entrevista se deu na própria sede da empresa, potencializando a observação direta como fonte de evidências; para tanto após a entrevista, pode-se sistematizar as observações apontando algumas das relações acordes com a leitura teórica. Quanto aos registros disponibilizados em ambiente virtual, várias das informações técnicas e históricas mencionadas pela entrevistada puderam ser confirmadas e, inclusive, a própria participante sugeriu uma análise do material da página da empresa. Ainda que a precisão das informações encontradas na internet possa ser parcial, Yin (2015) salienta a crescente disponibilidade de informações e a decorrente utilidade às pesquisas.

A definição da empresa participante partiu de conversas com informante chave que indicou a empresa potencial para o estudo. A empresa selecionada foi contatada para verificar a disponibilidade e interesse em participar da pesquisa, assim como para agendamento de entrevista. A mesma foi realizada com um membro da diretoria, responsável técnica, na sede da empresa, na sala de reuniões da diretoria, com duração aproximada de uma hora e trinta minutos; a colaboração da entrevistada foi imprescindível, respondendo a todos os questionamentos propostos. O deslocamento até a empresa foi com recursos próprios.

Após a aplicação do roteiro de entrevista, realizou-se a transcrição do áudio gravado sob consentimento da entrevistada. Os procedimentos de análise foram direcionados à análise de conteúdo temático-categorial. Esse tipo de análise requer, após a transcrição, a chamada leitura flutuante de caráter intuitivo (Oliveira, 2008), possibilitando detectar elementos chave na leitura, acordes com 
as categorias preestabelecidas. Na sequência, assim como Oliveira (2008, p. 572) comenta, foram identificadas as unidades de registro traduzidas por elementos de um documento, ou seja, "a resposta de uma questão aberta, uma entrevista"; posteriormente agruparam-se as unidades de registro em acordo com as categorias analíticas previamente estabelecidas: sustentabilidade ambiental, social, econômica e relações de sustentabilidade com a tomada de decisão. O tratamento e apresentação dos dados foram realizado a partir de "descrições cursivas, acompanhadas de exemplificação de unidades de registro" - trechos da entrevista.

\section{Caracterização do caso estudado}

A empresa analisada caracteriza-se por sua tradição no agronegócio da Campanha Gaúcha, fundando suas atividades há mais de cinquenta anos nos ramos da agricultura e pecuária e, permanece, pela terceira geração, exercendo sua administração familiar. A administração e a diretoria do segmento vitivinícola são totalmente familiares, em que cada membro se responsabiliza por determinado ramo, como por exemplo, comercial, técnico e gerencial, contando com o apoio de profissionais contratados.

Com o intuito de diversificar a gama de atividades e produtos trabalhados pela empresa, em 2003 inicia o projeto para a produção de uvas viníferas com mudas importadas da Europa. Na sequência, em parceria com a Embrapa Uva e Vinho surge a pretensão de investigar o potencial da Região da Campanha para a vitivinicultura, processo que resultou na elaboração do primeiro vinho da empresa. Constatada a vocação da região para a atividade, a empresa se insere gradativamente no mercado, lançando vinhos brancos e espumantes agraciados com premiações reconhecidas em nível mundial. Uma década depois, ocorre o lançamento da estrutura projetada ao Enoturismo, com foco na valorização da cultura local e, proporcionando um ambiente para a produção de seus vinhos, em totalidade, produzidos a partir de uvas próprias.

A área total dos vinhedos compreendia, quando da pesquisa, 21,5 hectares destinados à produção de oito variedades de uvas viníferas, alcançando uma produção média de sete toneladas por hectare. Em volume de vinhos, considerando a média ao longo dos anos, a produção de uvas próprias permite uma estimativa de 140 mil litros de vinhos. A safra de 2016 demostrou uma produção de, aproximadamente, 90 mil litros, a baixo das estimativas, pois as condições climáticas se fizeram atípicas, o que respondeu na produção de vinhos, pois a vinificação é diretamente proporcional à produção do vinhedo próprio.

A empresa foi escolhida como caso emblemático do agronegócio e intensa relação com a sustentabilidade e os três pilares propostos (econômico, social e ambiental) por Elkington (1999). A tomada de decisão realizada pela família é permeada pela constante preocupação no tocante a noção de sustentabilidade e de inovação com olhar ao desenvolvimento e projeção de perspectivas para ações futuras desvelando destaque para sua competitividade de mercado. Nas seções que seguem, discute-se cada um dos pilares da sustentabilidade organizacional (aqui representados pelas categorias de análise deste artigo) e, em seção posterior, a relação da mesma com a tomada de decisão. 


\subsection{Sustentabilidade Ambiental}

A preocupação da sociedade com a sustentabilidade motiva um mercado consumidor mais exigente provocando a necessidade de os negócios rurais adaptarem suas formas produtivas às práticas mais limpas e sustentáveis. Isso encontra com iniciativas identificadas na empresa em estudo, pois a variável ambiental está presente na adoção de práticas realizadas com foco na redução de impactos ambientais que, concomitantemente, alcança o mercado consumidor da empresa (Claudino e Talamini, 2013). O depoimento demonstra que, nesse aspecto, a empresa antecipou demandas e, o adicionou ao seu desenho de negócio, revelando-o presente em suas decisões tanto cotidianas quanto estratégicas.

Nota-se que Maia e Pires (2011) comentam que, possivelmente, o processo decisório simplista e focado apenas no viés econômico pode ser o motivador de ações emergenciais por parte das organizações no que cerne a sustentabilidade ambiental. Entretanto, a empresa estudada parece superar essa visão, pois suas iniciativas, com foco na sustentabilidade ambiental, não demonstram serem isoladas, pelo contrário perpassam as decisões da diretoria. Isso pode ser constatado nos empreendimentos realizados, descritos na sequência.

As ações voltadas à sustentabilidade ambiental estão presentes desde a implantação inicial do vinhedo, mas algumas iniciativas são pontuadas pela entrevistada:

\footnotetext{
A gente quando iniciou com o vinhedo já tinha essa mentalidade, essa consciência, então. Mas assim, a principal ação do momento, de reconhecimento dos clientes é o parque solar, as placas solares. Desde de maio de 2016, 100\% da nossa energia é renovável, vem da transformação das células fotovoltaicas. Inclusive a gente está tendo excedente dessa produção. Isso gera créditos na rede (energia elétrica) e a gente consegue usar esses créditos em dois anos (ENTREVISTADA).
}

A propriedade onde se localizam os vinhedos comerciais é averbada com reserva legal, a qual descarta a introdução de quaisquer produtos químicos e, contribui para a preservação do Pampa Gaúcho. Na localidade foram identificadas duas espécies de pássaros ameaçados de extinção e, a vasta biodiversidade também é destacada por pesquisas realizadas no local. Outro fator remete ao propício clima da região para o cultivo de viníferas possibilitando o uso de maquinários sustentáveis, a exemplo da Lazo TPC, que realiza o controle de esporos de fungos que possam estar presentes nas plantas, através de choques térmicos e, ao mesmo tempo, aciona o metabolismo secundário ativando sua autodefesa.

O projeto da vinícola foi realizado a fim de reafirmar a postura sustentável.

\footnotetext{
Além disso aqui no projeto da vinícola, todo esse jardim são plantas nativas do Pampa Gaúcho. A gente só trouxe do campo para cá. Vocês viram assim que é bem natural, não é uma coisa mais podadinha, artificial. Não, é natural mesmo. Identificamos todas elas com os nomes científicos. Sempre quando recebemos turistas, o guia informa. Para valorizar a cultura da região (ENTREVISTADA).
}

O telhado da vinícola, por exemplo, capta água da chuva e armazena em hidrantes para o plano de combate de incêndios; a circulação de ventilação e luminosidade possibilitada pelas janelas tem o intuito de reduzir o consumo de energia; estação de tratamento de água a partir da utilização de água de açude; os resíduos do vinho, o bagaço da uva estava sendo utilizado em pesquisas, em parceiras com a Universidade Federal de Pelotas, para utilização na alimentação animal. 
Em suma, a empresa pensa grande parte de seus projetos focando a sustentabilidade ambiental. Nessa discussão, Callado (2010) traz a ideia de que, de modo geral, as práticas das empresas brasileiras ficam aquém do esperado, focando especialmente as dimensões ambiental e econômica, sendo que a primeira tem em vista, principalmente, a redução de agroquímicos. Como foi demonstrado, a empresa além da redução de químicos, atua, constantemente, em outras ações de caráter ambiental, o que mostra um caso que supera a visão exposta pelo autor.

Silva (2012) concorda com o autor anterior e acrescenta alguns elementos à ideia exposta, como a tentativa em reduzir práticas intensivas de produção que se configuram predatórias, mas ainda reflete sobre a necessidade da expansão da visão sobre a sustentabilidade. Levando em conta a realidade investigada, não se descarta que, possivelmente, a maioria das empresas do agronegócio permaneça focada em ações pontuais de redução do uso de químicos, mas casos como o exposto demonstram que a realidade da sustentabilidade ambiental aos poucos vai ampliando os caminhos a serem percorridos e, cada vez mais se inserem de forma efetiva nas decisões de investimentos das empresas.

\subsection{Sustentabilidade social}

Ainda que no agronegócio, a dimensão ambiental esteja mais presente nos debates sobre a sustentabilidade, a aplicabilidade do conceito requer atenção nos aspectos social e econômico (Silva, 2012) pois, por vezes esses aspectos são analisados em segundo plano, pondo em questionamento a noção de sustentabilidade. A dimensão social da sustentabilidade deve abarcar atividades direcionadas à educação, cultura e justiça social no âmbito da comunidade presente na localidade que a empresa se insere (Paz, Iserhard, e Kipper, 2015), assim como das pessoas que estão envolvidas diretamente com a organização.

Dentre os aspectos sociais da sustentabilidade cita-se o fator cultural. Esse aspecto é trabalhado pela empresa em estudo, tanto é que para valorizar as questões locais e as pessoas da região, todos os funcionários contratados são de origem do município.

Todos são (funcionários) residentes daqui. A gente prioriza por isso. Primeiro que estamos valorizando as pessoas da regiâo. Queríamos ajudar no desenvolvimento da região, essa é uma das principais ideias. De preferência trazer mais gente para conhecer a região. Então, tinham que ser pessoas da região, e as pessoas da regiāo sabem sobre a cultura. A gente não mostra só a parte técnica, a gente mostra um pouco da cultura da regiāo. E daí as pessoas que trabalham aqui sabem como ninguém falar de como é o gaúcho, o que é o Pampa Gaúcho, e falam com muito orgulho (ENTREVISTADA).

Outro argumento sobre a valorização dos aspectos regionais pode ser vislumbrado no projeto de paisagismo da vinícola comentado anteriormente. Todo o jardim é composto de plantas nativas do Pampa Gaúcho, as quais foram transplantadas do campo e identificadas com seus nomes científicos. Nota-se que aqui há semelhanças com o que Beuron et al. (2014) atribuem à importância dos funcionários sobre o conhecimento da postura sustentável da empresa. Tanto em relação à valorização das pessoas nascidas na região quanto à transmissão dos valores culturais repassados; assim trabalha-se de forma estrutural, em que a empresa transmite aos seus funcionários os valores de sustentabilidade. 
Em relação à capacitação de funcionários são realizados treinamentos tanto na área técnica, mais focados nos enólogos, quanto em relação ao uso dos Equipamentos de Proteção Individual direcionados à toda a equipe de trabalho. Já nas ações direcionadas à aproximação com a comunidade em geral são preparados momentos para visitações de escolas, grupos de idosos, Rotary, Associação de Pais e Amigos dos Excepcionais (APAE). Para as crianças são realizadas ações educativas direcionadas ao consumo e benefícios do suco de uva; para os professores é estimulada a inserção da temática nos conteúdos programáticos das disciplinas.

\footnotetext{
Para crianças a gente fala em suco de uva. Usamos outro linguajar para as crianças, mostramos um vídeo sobre os benefícios do suco de uva em desenho animado. A gente que dar base. (ENTREVISTADA).

Além das crianças surgiu um pedido de uma escola para trazer todos os professores da escola. Achei ótimo! Preparamos também um tour mais direcionado, dando dicas de onde a gente acha que poderiam falar em cada matéria, da planta da videira, como é o ciclo dela, quanto tempo demora para produzir, é uma planta perene... por exemplo isso na biologia (ENTREVISTADA).
}

Em suma, as iniciativas na dimensão social perpassam a busca pela valorização do elemento cultural junto a contratação de pessoas naturais da região, algumas ações de treinamento dos funcionários até iniciativas que aproximem a comunidade da empresa. Para uma empresa inserida no agronegócio, as ações da dimensão social se destacam ao comparar com outros estudos como o de Allegretti (2013) que alega a fragilidade desta dimensão em sua pesquisa em termos de segurança e qualificação de mão de obra.

Considerando que a dimensão social se relaciona ao bem-estar dos envolvidos com a empresa e às iniciativas de responsabilidade social (Maia e Pires, 2011), percebe-se um esforço para integrá-la em suas decisões. Ainda que a dimensão social perpasse por ações pontuais e se fortaleça em aspectos culturais, na empresa em estudo. Posto isso, a próxima dimensão - a econômica - a ser descrita completa o tripé da sustentabilidade. Aqui, faz-se a ressalva de que a perspectiva apresentada remete ao olhar da empresária; acresce-se às limitações a falta da perspectiva dos funcionários da empresa, motivando pesquisas para o fazerem.

\subsection{Sustentabilidade Econômica}

A dimensão econômica, juntamente com a dimensão ambiental - já citada - são as que mais se destacam no setor empresarial brasileiro. As questões relacionadas à sustentabilidade econômica direcionam os esforços para a melhoria dos índices de rentabilidade e lucratividade (Callado, 2010). Importância semelhante à dimensão econômica é atribuída por Mamede (2013) ao estudar empresas de diferentes ramos em Portugal, como mencionado previamente.

A sustentabilidade econômica também pode ser verificada em iniciativas que visam a otimização e eficiência dos processos.

É uma indústria. Então tu tenta cada vez mais otimizar os processos, ser mais eficiente em cada processo. A gente inaugurou em 2013, e conseguiu fazer todas as etapas do vinho aqui, e com certeza a gente conseguiu reduzir muito os custos. Também a redução de custos, fazendo mais pesquisas na parte de escolha de fornecedores, na compra de insumos. A gente pesquisa muito (ENTREVISTADA). 
A realização de todas as etapas do vinho na vinícola própria, a partir de 2013, possibilitou redução significativa dos custos e, o desenvolvimento de pesquisas específicas para a escolha de fornecedores. Entretanto, alguns aspectos particulares ainda são conservados pelos consumidores de vinhos, como por exemplo, garrafas maiores e mais pesadas, que por vezes são atribuídas à qualidade do vinho, contribuindo para o aumento dos custos.

Todavia, essa característica se mantém em um dos 20 rótulos trabalhados pela empresa, os demais, apesar do vidro permanecer como matéria prima, prima-se por garrafas mais leves que respondem no valor do frete. Ademais, desde o início do projeto buscou-se máquinas importadas e especializadas que respondessem tanto em qualidade como em redução de custos. Ao longo do tempo os processos foram sendo melhorados, como por exemplo, a introdução do Programa de Alimentos Seguros implantado pelo Instituto Brasileiro do Vinho (IBRAVIN) que, além de responder pela qualidade e segurança do vinho, possibilita maior eficiência respondendo com redução de custos de transação.

A experiência ilustrada pela empresa revela que a sustentabilidade econômica é pensada a partir de ações programadas que incluem a inserção de tecnologias que trabalham diferentes elementos associados à redução dos custos. Nesse sentido, a sustentabilidade econômica transcende as decisões mais simples e rotineiras como apontam Maia e Pires (2011) sendo o foco da dimensão econômica. Não que se esvazie de decisões cotidianas, mas demonstra que há outros fatores a serem considerados na dimensão econômica da sustentabilidade.

A associação da empresa a uma imagem de sustentabilidade é outro fator que responde em termos econômicos, porém há dificuldades em mencionar a parcela representativa nas vendas.

Nunca vamos conseguir mensurar, a gente não sabe se é $20 \%$ das vendas que influencia, se é $30 \%$, se é $10 \%$, mas, como a vinícola é turística agente tem esse feedback diário das pessoas que vem aqui, o quanto elas valorizam isso, a gente nota que é muito (ENTREVISTADA).

A distinção do produto é percebida através dos meios de comunicação e divulgação da empresa para com seus clientes, já que, ainda, a empresa não conta com identificação em rótulos. Em suma, a dimensão ambiental da sustentabilidade corrobora significativamente para o fortalecimento da dimensão econômica. Desta forma, evidenciam-se outros componentes além dos discutidos por Paz, Iserhard e Kipper (2015) como os principais motivadores da sustentabilidade econômica (controle financeiro) e da ambiental (cumprimento da legislação).

\subsection{Sustentabilidade e a relação com a tomada de decisão}

Foi possível apontar os critérios de sustentabilidade (contemplando as três dimensões) inseridos na lógica decisória, perpassando desde decisões cotidianas até decisões mais elaboradas estrategicamente. Essa discussão é trazida por Arora et.al. (2016), em que questionam como inserir a sustentabilidade na tomada de decisão, pois a relação com os três pilares não é estática, se modifica conforme o contexto, mas permanece como fundamental para a tomada de decisão. No caso em estudo, nota-se essa dinamicidade marcada pelos autores, mas a resposta sobre como inserir a sustentabilidade nas decisões se distancia de algo mensurável, pois ela permeia a racionalidade da empresa. 
ConfiguraçóesTatielle Belem Langbecker | Thiago Antonio Beuron

As decisões que demandam maiores investimentos, por se tratar de uma empresa com administração familiar, percorrem o caminho da emoção e da razão. As iniciativas de projetos ousados partem, em grande medida, de motivações sentimentais, mas que são avaliadas em termos de viabilidade para posterior ponderação sobre sua factibilidade. As decisões técnicas e cotidianas levam em conta experiências anteriores vinculadas à relação custo-benefício. E, a relação com a apreciação de familiares é mais voltada às decisões sobre o layout e nomes dos rótulos, presente nas decisões do que e como será realizada a apresentação do produto ao mercado, destacando-se a importância das diferentes opiniões dos membros da família.

Verifica-se que as decisões são interpostas ora pelo consenso familiar, ora pela experiência cotidiana, por motivações de fundo emocional, mas avaliadas tecnicamente para a aplicabilidade. A sustentabilidade, especialmente, a ambiental, percorre os caminhos das diferentes decisões contribuindo para firmar a empresa como competitiva no mercado dos vinhos. Isso é apontado por Mamede (2013) como importante elemento para a permanência em mercados competitivos, ou melhor, a habilidade de adaptar o modelo de gestão aos diferentes cenários constantemente em mudança, em que a inserção da sustentabilidade, tanto em âmbito estratégico como operacional, configura-se como uma dessas mudanças exigidas.

Desta forma, a motivação para inserir a sustentabilidade como um elemento do processo decisório perpassa tanto pela primazia da consciência sustentável em perspectiva ambiental, social e econômica como exerce função estratégica no posicionamento de mercado. Isso concorda com o que Löbler (2005) comenta sobre as influências que o processo decisório carrega. As ideias e os valores dos gestores que representam o processo decisório, assim como das inter-relações entre os atores (neste caso os membros da família e demais representantes dos elos da cadeia) são os principais influenciadores dos rumos de um processo decisório.

\section{Considerações finais}

Considerando que o tripé da sustentabilidade passa a compor a problemática dos processos decisórios empresarias (Maia e Pires, 2011) identificou-se o alinhamento dos preceitos da sustentabilidade ao processo decisório em determinada empresa rural em Dom Pedrito/RS. A literatura aponta elementos que deveriam estar presentes nas três dimensões para considerar aplicada a noção de sustentabilidade em processos decisórios, assim como, a complexidade em fazê-la. Na figura 1, são representados os elementos e características que moldam a tomada de decisão familiar, cotidiana e estratégica. Os traços contínuos representam a concomitância entre princípios e estratégias e, os traços pontilhados revelam as relações entre os elementos da sustentabilidade. 
Figura 1 - Características e elementos da tomada de decisão

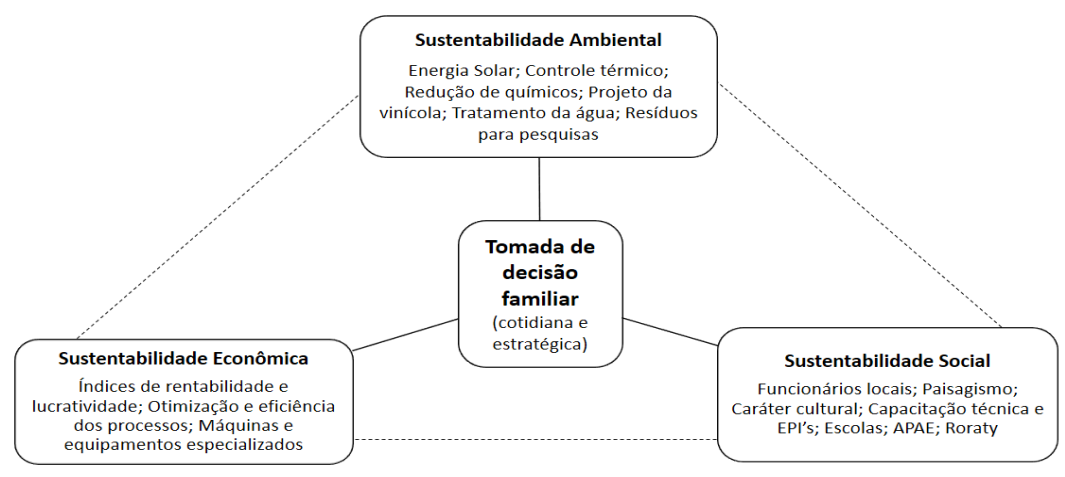

Fonte: Elaboração própria, 2019.

Nesse sentido, o questionamento acerca das perspectivas aplicadas na tomada de decisão, revela a adoção das três perspectivas da sustentabilidade nesse processo, em âmbito organizacional. Ainda possibilita a inferência de que os aspectos ambiental, social e econômico estão presentes em decisões cotidianas e estratégicas. Isso pode ser constatado a partir da construção realizada em cada objetivo específico.

A caracterização do processo decisório da empresa rural em estudo - primeiro objetivo específico - evidencia a participação familiar em decisões estratégicas, como investimentos em infraestrutura e aspectos relevantes dos produtos. Para estas decisões são ponderadas tanto a emoção quanto a razão, no intuito de analisar as alternativas mais satisfatórias para o negócio. As decisões técnicas e cotidianas contemplam o portfólio de experiências dos integrantes da empresa, buscando alternativas que mais se aproximem da melhor relação custo-benefício direcionada aos princípios de sustentabilidade adotados pela empresa.

O segundo objetivo específico identificou os critérios de sustentabilidade no processo decisório. Foram encontrados elementos que compunham as três dimensões da sustentabilidade (ambiental, social e econômica), como, investimentos em infraestrutura visando aspectos ambientais e econômicos, iniciativas em aproximação com a comunidade local, exploração de elementos culturais; destacando-se atenção especial ao viés ambiental.

Levando em conta que o projeto da vinícola se insere em uma lógica de sustentabilidade organizacional, o terceiro objetivo específico verificou as motivações para a inserção da sustentabilidade como elemento do processo decisório, as quais perpassam desde a consciência de trabalhar a sustentabilidade como princípio, até os ganhos de mercado que são resultantes.

Em termos gerais, o estudo evidencia que para efetivamente ocorrer decisões fundamentadas na noção de sustentabilidade, se faz necessária uma integração entre os três preceitos, ou seja, desdobrando em complementariedades entre o ambiental, econômico e social. Ainda com base no estudo, observa-se que para haver "decisões sustentáveis" é necessário que o processo seja integrado tanto às decisões do dia-a-dia como em decisões estruturais e estratégicas; enfim, pressupõe-se um pensar e agir com base em um esquema decisório imerso nos pilares da sustentabilidade. 
As ressalvas de um trabalho exploratório, ainda em se tratando de um estudo de caso único, devem ser sublinhadas, pois trazem limitações para a realização de generalizações podendo representar pequena parcela da realidade. Mesmo assim, permitiu revelar situações emblemáticas encontradas no agronegócio da região da Campanha. Portanto, é relevante que sejam realizados outros estudos que ampliem o escopo de análise da problemática, inclusive contemplando pesquisas quantitativas e atividades do agronegócio de diferentes ramos de produção, assim como, investigações em outras regiões tanto do estado quanto do país.

Algumas sugestões hipotéticas instigam pesquisas sobre a temática, talvez, na região em estudo, as atividades voltadas à uva e vinho, por serem mais recentes que as demais, já surjam inseridas na lógica da sustentabilidade. E as atividades mais tradicionais, criação de gado, cultivo de arroz e soja, também permeiam estas preocupações? Seria de interesse investir em infraestrutura, por exemplo, para despertar e despontar a relação com a sustentabilidade? Ou as suas diferentes características mercadológicas não estariam estimulando uma inserção efetiva nos três pilares da sustentabilidade?

\section{Referências}

Allegretti, G. (2013). Integração das dimensóes social, ambiental e econômica na terminação de suinos: construção de indicadores de desempenho e validação em um município do Rio Grande do Sul. (Dissertação de Mestrado) - Programa de Pós-Graduação em Agronegócios, Universidade Federal do Rio Grande do Sul - UFRGS, Porto Alegre, RS, Brasil, 2013.

Andreatta, T. (2009). Bovinocultura de corte no Rio Grande do Sul: um estudo a partir do perfil dos pecuaristas e organizaçáo dos estabelecimentos agrícolas. (Tese de Doutorado) - Programa de PósGraduação em Desenvolvimento Rural, Universidade Federal do Rio Grande do Sul - UFRGS, Porto Alegre, RS, Brasil, 2009.

Arora, P., Peterson, N. D., Bert, F., e Podesta, G. (2016). Managing the triple bottom line for sustainability: a case study of Argentine agribusinesses. Sustainability: Science, Practice e Policy, 12 (1), $60-75$.

Batalha, M. O. (Org.). (2008). Gestão Agroindustrial. (3a ed., Vol. 1) São Paulo: Atlas.

Beuron, T. A., Madruga, L. R. R. G., Ávila, L. V., Galvão, F. F., e Schuch Jr., V. F. (2014). Uma análise dos valores organizacionais sob a perspectiva da sustentabilidade: contribuiçôes a partir da percepção dos empregados. Revista Gestão e Sustentabilidade Ambiental, 3 (1), 165 - 184.

Brasil. Ministério da Agricultura, Pecuária e Abastecimento. Agrostat-Estatística de Comércio Exterior do Agronegócio Brasileiro. Recuperado em 8 agosto, 2019, de http://indicadores.agricultura.gov.br/agrostat/ index.htm

Callado, A. L. C. (2010). Modelo de mensuração de sustentabilidade empresarial: uma aplicação em vinicolas localizadas na Serra Gaúcha. (Tese de Doutorado) - Programa de Pós-Graduação em Agronegócios, Universidade Federal do Rio Grande do Sul - UFRGS, Porto Alegre, RS, Brasil, 2010. 
Claudino, E., e Talamini, E. (2013). Análise do Ciclo de Vida (ACV) aplicada ao agronegócio: uma revisão de literatura. Revista Brasileira de Engenharia Agrícola e Ambiental, 17 (1), 77 - 85.

Dalcin, D. (2010) O processo de tomada de decisão em agricultores de Boa Vista das Missóes - RS. (Dissertação de Mestrado) - Programa de Pós-graduação em Extensão Rural, Universidade Federal de Santa Maria - UFSM, Santa Maria, RS, Brasil, 2010.

Elkington, J. (1999). Cannibals with forks: the triple bottom line of 21st century business. (2a ed) Capstone.

Feix, R. D., e Leusin, S. J. (2015). Painel do Agronegócio no Rio Grande do Sul-2015. Porto Alegre: FEE.

Flick, U. Uma introdução à pesquisa qualitativa. (2004). (2a ed) Porto Alegre: Bookman.

Fonte, C. S., Colombelli, G. L., Lorenzi Jr., D., Obregon, S. L., Brito, L. C., e Moura, L. R. I. (2016, Setembro). O processo de tomada de decisão dos agricultores: um estudo de campo no município de Cachoeira do Sul. Anais do Fórum Internacional Ecoinovar - $1^{a}$ Conferência Internacional de Sustentabilidade e Inovação, Santa Maria, RS, Brasil, 5. Recuperado de http://ecoinovar.com.br/cd2016/ arquivos/artigos/ECO1139.pdf

Gil, A. C. Métodos e técnicas de pesquisa social. (2008). (6a ed) São Paulo: Editora Atlas.

IBGE - Instituto Brasileiro de Geografia e Estatística. (2017). Sistema IBGE de Recuperação Automática (SIDRA). Recuperado em 8 agosto, 2019, de https://sidra.ibge.gov.br/pesquisa/pam/tabelas

Löbler, M. L. (2005). Processamento da informação: uma avaliação dos diferentes niveis de conhecimento no processo de decisão. (Tese de Doutorado) - Programa de Pós-graduação em Administração, Universidade Federal do Rio Grande do Sul - UFRGS, Porto Alegre, RS, Brasil.

Maia, A. G., e Pires, P. S. (2011). Uma compreensão da sustentabilidade por meio dos níveis de complexidade das decisões organizacionais. Revista de Administração Mackenzie/RAM, 12 (3), 177 206.

Mamede, P. M. F. (2013). Medição da sustentabilidade empresarial. (Dissertação de Mestrado) Faculdade de Economia da Universidade de Coimbra, Universidade de Coimbra - UC, Coimbra, Portugal.

Marcovitch, J. Prefácio. (2000). Em Zylbersztajn, D., e Neves, M. F. Economia e gestão dos negócios agroalimentares. (pp. IX-X) São Paulo: Editora Pioneira.

Mariotto, F. L., Zanini, P. P., e Moraes, G. H. S. M. M. (2014). What is the use of a single-case study in management research? Revista de Administração de Empresas - ERA, 54 (4), 358-369.

Minayo, C. S. (2007). O desafio da pesquisa social. Em Deslandes, S. F., e Minayo, C. S. Pesquisa Social: teoria, método e criatividade. (26a ed., pp. 9-29) Petrópolis: Vozes.

Moritz, G. O., e Pereira, M. F. (2006). Processo decisório. Florianópolis: SEAD/UFSC. 
ConfiguraçóesTatielle Belem Langbecker | Thiago Antonio Beuron

Oliveira, D. C. (2008). Análise de conteúdo temático-categorial: uma proposta de sistematização. Revista de Enfermagem, 16 (4)., 569-576.

Paz, F. J., Iserhard, L. F. Z., e Kipper, L. M. (2015). Indicadores para sustentabilidade organizacional em empresas gaúchas da região do Pampa Gaúcho: um estudo exploratório. Revista Eletrônica de Ciência Administrativa (RECADM), 14 (2), 92-109.

Silva, D. B. (2012). Sustentabilidade no Agronegócio: dimensóes econômica, social e ambiental. Comunicação \& Mercado/UNIGRAN, 1 (3), 23-34.

Yin, R. Estudo de caso: planejamento e métodos. (2015). (5a ed) Porto Alegre: Bookman.

Zylbersztajn, D. (2014). Coordenação e governança de sistemas agroindustriais. Em Buainain, A. M., Alves, E., Silveira, J. M., Navarro, Z. (Orgs.), O mundo rural no Brasil do século 21: a formação de um novo padráo agrário e agrícola. (pp. 267-294). Brasília: Embrapa. 